\title{
Geospatial data homogenization and processing for integrated assessment of urban and natural resources and risks

\author{
A pilot case for Lazio Region (Italy)
}

Andrea SPASIANO, Water Resources Research and Documentation Center, University for Foreigners of Perugia, Italy

Umberto BARTOCCINI, Water Resources Research and Documentation Center, University for Foreigners of Perugia, Italy

Fernando NARDI, Water Resources Research and Documentation Center, University for Foreigners of Perugia, Italy

\begin{abstract}
This contribution illustrates the data, methods and geospatial intelligence solutions that were produced, by means of a web GIS application, for the integrated analysis and mapping of open geo data gathered from regional spatial risk and landscape resource planning in Italy. The aim was to developed and test a tool support regional planners and decision makers for sustainable and effective management and regeneration of urban spaces. The work assumes that any urban regeneration initiative must rely on an adequate knowledge of environmental and cultural resources and risk factors affecting the geographic context of reference. Accessing geographic knowledge base across multiple sectors and level of education and experience is an important, but challenging, task, when the audience spans from high level researchers and professionals to the general public (e.g. citizens). For this purpose, a web application has been developed for the interactive visualization and query of geospatial data pertaining to regional land management plans adopted in Italian normative framework with specific geographic focus on central Italy. This work, processed at the prototype level, illustrates the characteristics and potential of the solution in the territorial context of Lazio (regional administrative boundary of the city of Rome), integrating geospatial data on the Regional Spatial Landscape Plan (PTPR) and the Flood risk Management Plan (PAI). This case study is an exemplary model that can be replicated in other regional contexts.
\end{abstract}

\section{Keywords}

landscape, GIS, open data, flood risks, urban planning

\section{Introduction}

Safe and sustainable urban and landscape protection and development are generally achieved by identifying and zoning the areas characterized by homogeneous resources and risk conditions. Planning activities at regional scale requires a high level of knowledge of environmental and anthropogenic systems and mutual connections. Landscape plays an essential role in the dynamics of local development and in the definition of territorial assets (Marcucci, 2000; Von Haaren, 2002). This general principle 
applies to any regional urban and landscape planning project from natural hazard management and planning (Directive 2007/60/EC on the assessment and management of flood risk; Mysiak et al., 2014) to cultural and natural landscape protection (Marcucci, 2000; Von Haaren, 2002; Fusco Girard \& De Toro, 2007; Jeong et al., 2013; Gisotti, 2017; Franco et al., 2018).

In Italian legislation, the landscape is a key driver of urban and regional planning, orienting the geospatial decisions and policy making in the matter of environmental sustainability; management of natural risks; protection and enhancement of the cultural heritage; organization of socio-economic activities; land use and consumption; management of urban sprawl and infrastructure networks; environmental and urban regeneration activities. Monitoring and evaluating risk factors, degradation of the landscape and connection between human, cultural and environmental values thus become fundamental in the definition of urban governance on different levels of geographic and administrative scale (Magnaghi, 2017). The evolution of geospatial technologies - associated with the increasing availability and diffusion of open data used in the drafting of regional landscape and hydrological risks plans - opens new scenarios of geographic analysis for resource management environmental and cultural landscape. This work presents the creation of a prototype for the integrated mapping of land use plans, using GIS technologies. It has been developed as part of an ongoing research of Water Resources Research and Documentation Center (WARREDOC)-University for Foreigners of Perugia. The prototype is functional to provide a digital and innovative solution for landscape assessment and management in connection with hydrogeological risk factors and urban degradation.

The theoretical substratum that supports this work is represented by normative references and programmatic guidelines provided by the European Landscape Convention (2000), the Code of Cultural Heritage and Landscape (D.Igs. 42/2004) underlining the functional centrality of the landscape and of the environmental and cultural resources within the spatial design and the regeneration of marginal and abandoned areas (Civitarese Matteucci, 2005; Cartei, 2007; Marzuoli, 2008; Sciullo, 2008). In this perspective, the landscape constraint constitutes a normative tool to address urban transformations through sustainable practical actions aimed at the enhancement of ecosystem services (Gisotti, 2016; Salata et al., 2016) in terms of: soil maintenance, reducing the risks of hydrogeological stability, the costs of environmental degradation, educational activities, social inclusion, energy production and development of sustainable socio-economic activities (Poli, 2012).

GIS data and tools usually support the drafting of territorial management plans - including Regional Landscape Plans (Piano Paesaggistico Regionale - PPR), Regional Spatial Landscape Plans (Piano Territoriale Paesaggistico Regionale - PTPR), Hydrogeological Planning (Piano di Assesto Idrogeologico PAI) and General Regulatory Plans (Piano Regolatore Generale - PRG) adopted at municipal level through the digitization of environmental, landscape and archeological features. Public databases collect and make available open data relating to the composition of landscape constraints, environmental and cultural assets (including punctual and linear), infrastructure networks, areas at risk. At the administrative level, the use of GIS technologies is limited to the phase of recognition and mapping of landscape features (Carver et al., 2012). The technical standards for the implementation of land use plans in fact provide to produce plan maps, as a support tool for knowledge and planning of the geospatial transformations and connections. The sectionalization and division of administrative competences in the field of spatial planning - associated with the multiplicity of actors involved, however, implies technical and structural differences in the drafting and adoption of plans. Differences that are also reflected in the production, technical structure, and availability of related geospatial data through institutional web GIS platforms (Spasiano \& Nardi, 2019). These problems are, therefore, an obstacle to an integrated mapping of the geospatial features, risk factors and public heritage. 
The aim of this work is therefore the development of a tool to support strategic decisions (DSS) on a webbased GIS for an integrated and dynamic reading of the different spatial planning plans (PPR, PTPR, PAI) through a procedure of homogenization and standardization of the available geospatial information. Homogenization means a data-processing procedure designed to combine differently structured information within unique and descriptive layers of information on the essential characteristics of natural, agro-forestry and historical elements and systems-settlements that connote the landscape and territorial structures (Spasiano \& Nardi, 2019).

\section{Methodology}

The proposed solution is based on the implementation of a GIS data model gathering, homogenizing and visualizing thematic layers describing regional urban and landscape features. The purpose of this procedure is to identify the basic elements of urban and regional structures within four categories of cartographic layers (table 1). These thematic categories, then, allow a rapid visualization and querying of geospatial data, even for non-expert users, by dynamic and intuitive dashboard.

The methodological procedure for defining the homogenized data model and developing of the prototype is structured as follows:

- Open data acquisition from institutional portals related to Regional Plan of Lazio;

- Homogenization of data and standardization by identifying common and unambiguous table fields (table 2);

- Definition of homogeneous thematic categories for final data merging (table 1).

The case of Lazio Region represents a pilot study, using geospatial data relating to landscape constraints defined pursuant to Articles 134 and 142 of Legislative Decree no. 42/2004 as part of the Regional Landscape Territorial Plan (2007) and risk areas under the Hydrogeological Plan.

The univocal informative layers elaborated describe, therefore, the structural characteristics of the different plans of territorial planning (table 1), through which to supply an integrated and dynamic reading on digital cartographic support, developed with solutions web GIS.

\begin{tabular}{|l|l|l|}
\hline Layer & Original file & Source \\
\hline \multirow{2}{*}{ Water } & Flood risk areas & \\
\hline \multirow{2}{*}{ Archeology } & Lakes coasts \\
\hline & Marine coasts & \\
\hline \multirow{2}{*}{ Landscape Heritage } & Archeological areas & \multirow{2}{*}{ Lazio Region Open Data } \\
\hline Green & Archeological interest areas \\
\hline & Common goods \\
\hline & Historical town and villages \\
\hline & Protected areas \\
\hline & Wetlands \\
\hline & Special protection areas \\
\hline & Woods and forests \\
\hline
\end{tabular}

Table 1 - List of univocal informative layers 


\begin{tabular}{|l|l|}
\hline Table field & Description \\
\hline FID & Feature ID \\
\hline Name_file & Original name file \\
\hline layer & Related homogenized and univocal category \\
\hline NAME & Reference place/toponym \\
\hline
\end{tabular}

Table 2 - Table fields of univocal layers

\subsection{Procedure}

Once the data has merged, the information layers obtained has been subjected to further processing steps. Such post-processing has the aim to facilitate the graphical visualization and the interrogation of the data in web GIS environment. Considering the significant spatial scale of reference and the need to have a flexible web navigation tool for the user, the information layer has been the subject of a graphic simplification of geometries able to ensure the dynamic visibility of the elements in the final product but using a manageable number of features. The original geometries in fact presented a level of graphic detail too high to be properly displayed in the Web GIS environment. The procedure applied in this respect provided for:

- A unified landscape layer conversion to 4 raster datasets of different resolution (250 m; 100 $\mathrm{m} ; 50 \mathrm{~m} ; 25 \mathrm{~m}$ ), as illustrated in figure 1;

- A second conversion of each raster dataset into as many vector layers.



Figure 1. Layers' conversion procedure.

These steps, while simplifying the level of graphic detail, ensure an in-depth view of the information contained in every single feature (figure 3). At the end of these steps tabular joins were made with the original data to connect every single cell of the final layers (in their different resolutions) to the initial informative attributes (Figure 4). 




Figure 3. Final cartographic representation.

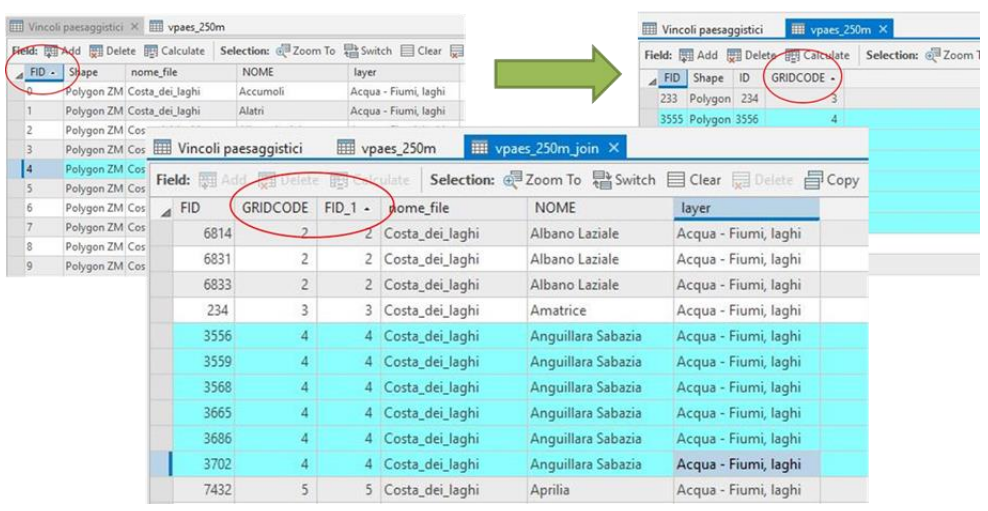

Figure 4. Table join procedure.

\section{Description of the web GIS application and results}

\subsection{Dynamic map}

Dynamic map is the main component of the application. The dynamic visualization of the map allows the user to visualize on more levels of scale the mapped elements. Depending on the display scale, layers turn on and off automatically, activating and/or deactivating the same layer on the landscape with different pixel sizes. On the scale of 1:300,000, the point elements are also displayed, representing sites of environmental, cultural or architectural interest. Clicking directly on the item of interest opens the pop-up window that shows the essential information of the data. 


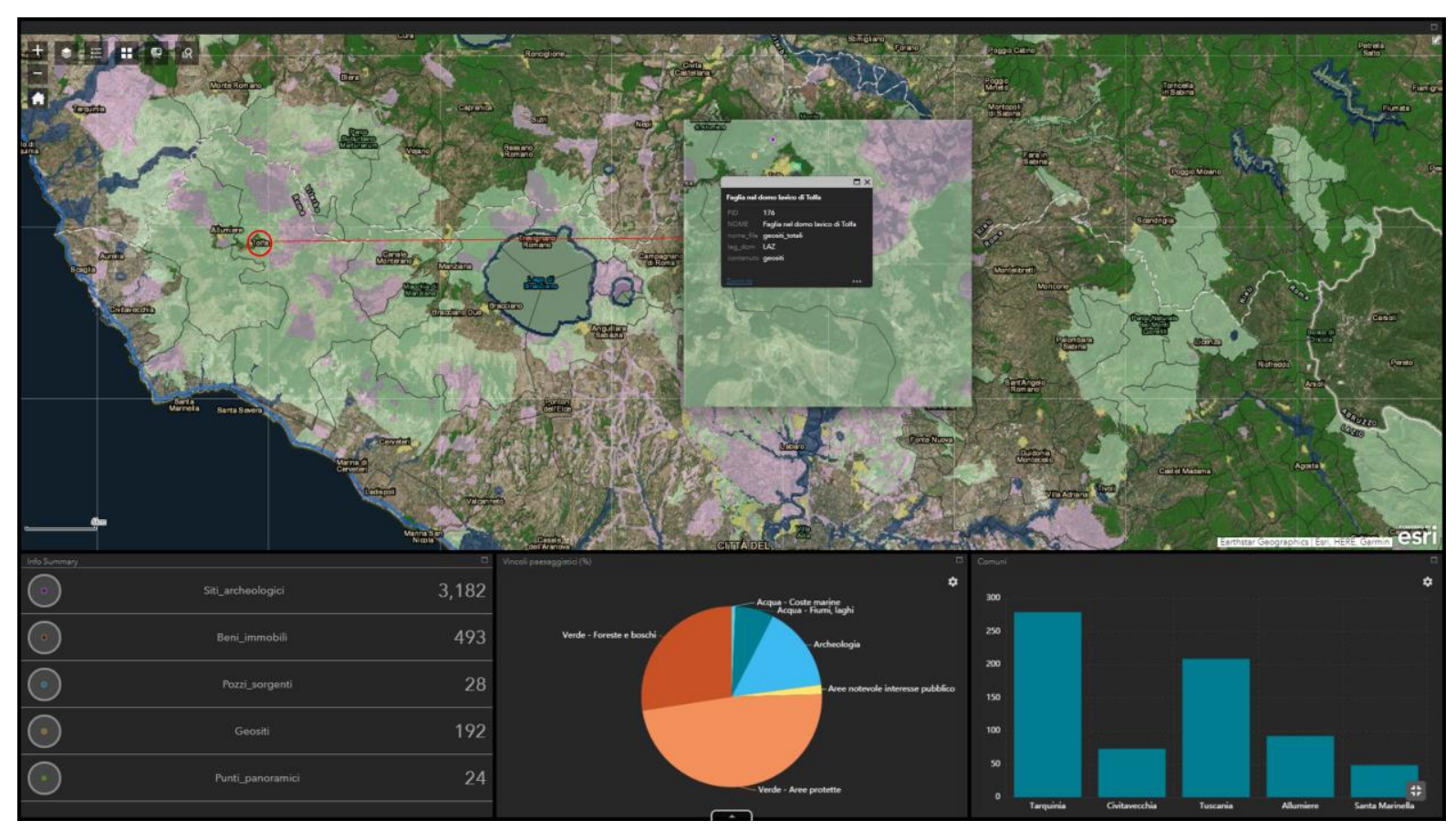

Figure 5. A screen from landscape webGIS.

\subsection{Widget}

The application is enhanced by 5 tools (widgets) as well as zoom (+/-) and "home" functions:

- Layer list, to turn on/off the layers to display. The feature also allows users to zoom in on the item, set transparency and visibility range, disable pop-up and recall the related attribute table and layer details hosted on the webGIS cloud.

- Legend, a dynamic legend depending on the elements illustrated in the screen extension.

- Basemap gallery, which allows you to customize map visualization.

- Screening, which allows users to select attributes by typing the toponym of a specific location, manually drawing a polygon, loading a shapefile from local device, or setting the geographical coordinates or a buffer distance. The Report command returns a summary list of items that fall on the selected area and allows download in tabular format in csv locally.

- Query, for spatial queries on the data that can be exported both as a csv table and as features class.

\subsection{Infographics}

The infographics are displayed at the bottom of map. Infographics are dynamic as they are updated according to the zoom screen on the map. The application has three infographics:

- INFO SUMMARY: shows the number of punctual elements present on the screen. When points are activated, the list of displayed attributes is made available.

- PIE CHART: a dynamic pie chart that illustrates the composition in percentage terms of the type of constraint that falls on a specific screen. 
- BAR CHART: A bar chart showing the extension in square kilometers of the municipal areas concerned on the screen.

\section{Discussion}

This pilot study demonstrates the opportunities offered by GIS for the supply of vertical solutions that, in addition to the illustrative purpose, provide crucial data and summary information to support decisionmaking processes in urban planning and regeneration activities. The prototype, here described, aims to illustrate, in a single solution, the information resulting from the geospatial processing of open data related to different spatial plans. The web GIS solution presented is equipped with a thematic cartography and with query and spatial analysis tools linked to infographics and other elements that feature a complete and functional dashboard for decision making in management projects territorial. At present, its main functions are:

- Acquisition and integration of spatial information and geographical data;

- Cataloguing and filing of information in homogeneous layers of information;

- Mapping and representation of the main land use plans (Landscape Plans, PAI);

- Spatial queries and analyses of data;

- Geo-statistical processing of spatial information;

- Aggregation and return of geo-referenced data.

The broader project impacts cover a vast range and type of professionals and stakeholders interested in landscape resource and urban regeneration management and assessment. The solution has been designed as a versatile and flexible tool to support planning and regeneration activities with the support of data for knowledge and analysis of the landscape and risk factors that characterize the spatial structure. In particular, the solution has been designed for:

- Addressing urban regeneration and renewal actions by mapping cultural ecosystem services and specific landscape resources (Fusco Girard \& De Toro, 2007; Caspersen and Olafsson, 2010; Koppen et al., 2014; Mele \& Poli, 2017; Franco et al., 2018)

- Identification of best localization factors for the construction, installation and restoration of building and infrastructure complexes according to the landscape and hydrogeological legal constraints (Gorsevski et al., 2012; Rikalovic et al., 2014; Gavrilidis et al., 2016)

- Support for sustainable tourism activities integrated with the local landscape and ecosystem services (Caspersen and Olafsson, 2010; Carver et al., 2012; Koppen et al., 2014)

- Addressing the land uses allowed by the structural characteristics of landscape, such as agricultural, urbanized, productive, commercial (Manos et al., 2009; Gorsevski et al., 2012; Rikalovic et al., 2014; Gavrilidis et al., 2016)

- Recognizing risks sensitive valuable areas under environmental and cultural profile

Future product implementations may result from the integration of citizen observation, as human sensors of territorial and environmental dynamics and processes (Goodchild, 2007). In this sense, the improvement of prototype consists in developing extensions for citizens' engagement with support of social media systems and digital technologies and devices (Lisjak et al., 2017; Assumpçao et al., 2018; 
Nardi et al., 2021; Spasiano et al., 2021). once the model has been perfected, it is also planned to be applied in different regional contexts.

\section{References}

Assumpção, T. H. et al. (2018) 'Citizen observations contributing to flood modelling: Opportunities and challenges', Hydrology and Earth System Sciences, 22(2), pp. 1473-1489. doi: 10.5194/hess-221473-2018.

Cartei G.F. (eds.) (2007), Convenzione Europea del Paesaggio e governo del territorio, Bologna, II Mulino.

Carver, S. et al. (2012) 'A GIS model for mapping spatial patterns and distribution of wild land in Scotland', Landscape and Urban Planning, 104(3-4), pp. 395-409. doi: 10.1016/j.landurbplan.2011.11.016.

Caspersen, O. H. and Olafsson, A. S. (2010) 'Recreational mapping and planning for enlargement of the green structure in greater Copenhagen', Urban Forestry and Urban Greening, 9(2), pp. 101-112. doi: 10.1016/j.ufug.2009.06.007.

Civitarese Matteucci, S. (2005), 'La pianificazione paesaggistica: il coordinamento con gli altri strumenti di pianificazione', Aedon, 3 [online]. Available at: http://www.aedon.mulino.it/archivio/2005/3/civitarese.htm (Accessed: 02/11/2021)

European Landscape Convention, 2000

Franco, S. F. and Macdonald, J. L. (2018) 'The effects of cultural heritage on residential property values: Evidence from Lisbon, Portugal', Regional Science and Urban Economics, 70, pp. 35-56. doi: 10.1016/j.regsciurbeco.2018.02.001.

Fusco Girard, L. and De Toro, P. (2007) 'Integrated spatial assessment: A multicriteria approach to sustainable development of cultural and environmental heritage in San Marco dei Cavoti, Italy', Central European Journal of Operations Research, 15(3), pp. 281-299. doi: 10.1007/s10100-0070031-1.

Gavrilidis, A. A. et al. (2016) 'Urban Landscape Quality Index - Planning Tool for Evaluating Urban Landscapes and Improving the Quality of Life', Procedia Environmental Sciences, 32, pp. 155-167. doi: 10.1016/j.proenv.2016.03.020.

Gisotti, M.R. (2016). 'Dal vincolo al progetto. Il quadro della pianificazione paesaggistica in Italia e una proposta per un modello operativo' in Magnaghi, A. (eds.) La pianificazione paesaggistica in Italia. Stato dell'arte e innovazioni. Firenze: Firenze Press University, pp. 1-33

Goodchild, M. F. (2007) 'Citizens as sensors: The world of volunteered geography', GeoJournal, pp. 211221. doi: 10.1007/s10708-007-9111-y.

Gorsevski, P. V. et al. (2012) 'Integrating multi-criteria evaluation techniques with geographic information systems for landfill site selection: A case study using ordered weighted average', Waste Management, 32(2), pp. 287-296. doi: 10.1016/j.wasman.2011.09.023.

Italian Cultural Heritage and Landscape Code (2004)

Koppen, G., Sang, Å. O. and Tveit, M. S. (2014) 'Managing the potential for outdoor recreation: Adequate mapping and measuring of accessibility to urban recreational landscapes', Urban Forestry and Urban Greening, 13(1), pp. 71-83. doi: 10.1016/j.ufug.2013.11.005. 
Lisjak, J., Schade, S. and Kotsev, A. (2017) 'Closing data gaps with citizen science? Findings from the Danube Region', ISPRS International Journal of Geo-Information, 6(9). doi: 10.3390/ijgi6090277.

Magnaghi A. (eds.) (2016), La pianificazione paesaggistica in Italia, Firenze, Firenze University Press.

Manos, B. D. et al. (2010) 'A DSS for sustainable development and environmental protection of agricultural regions', Environmental Monitoring and Assessment, 164(1-4), pp. 43-52. doi: 10.1007/s10661-009-0873-1.

Marzuoli, C. (2008) 'Il paesaggio nel nuovo Codice dei Beni Culturali', Aedon, 3 [online]. Available at: http://www.aedon.mulino.it/archivio/2008/3/marzuoli.htm (Accessed: 02/11/2021)

Mele, R. and Poli, G. (2017) 'The effectiveness of geographical data in multi-criteria evaluation of landscape services', Data, 2(1). doi: 10.3390/data2010009

Mysiak, J. et al. (2013) 'Flood risk management in Italy: Challenges and opportunities for the implementation of the EU Floods Directive (2007/60/EC)', Natural Hazards and Earth System Sciences, 13(11), pp. 2883-2890. doi: 10.5194/nhess-13-2883-2013

Nardi, F. et al. (2021) 'Citizens AND HYdrology (CANDHY): conceptualizing a transdisciplinary framework for citizen science addressing hydrological challenges', Hydrological Sciences Journal, 00(00), pp. 1-18. doi: 10.1080/02626667.2020.1849707.

Regione Lazio (2007), 'Piano Paesistico Territoriale Regionale-Relazione'

Rikalovic, A., Cosic, I. and Lazarevic, D. (2014) 'GIS based multi-criteria analysis for industrial site selection', in Procedia Engineering. Elsevier Ltd, pp. 1054-1063. doi: 10.1016/j.proeng.2014.03.090.

Salata S., Ronchi S. e Ghirardelli F. (2016), I servizi ecosistemici a supporto della pianificazione paesaggistica', Territorio, 77 (8)

Sciullo, G. (2008) 'll paesaggio fra la Convenzione e il Codice', Aedon, 3 [online]. Available at: http://www.aedon.mulino.it/archivio/2008/3/sciullo2.htm (Accessed: 02/11/2021)

Spasiano, A. and Nardi, F. (2019) 'A GIS-based fuzzy analysis for mapping the touristic potential in Lazio Region (Italy)', J-Reading - Journal of Research and Didactics in Geography, pp. 41-54. doi: 10.4458/2252-03.

Spasiano, A. et al. (2021), 'Towards a Transdisciplinary Theoretical Framework of Citizen Science: Results from a Meta-Review Analysis' Sustainability, 13(14), p.7904. doi: http://dx.doi.org/10.3390/su13147904. 